\title{
Percepção dos pais em relação à inclusão de crianças com Necessidades Educativas Especiais no ensino regular
}

\author{
Elisabete Matos Freitas* \\ Luisa Novais Arroja** \\ Paula Magalhães Ribeiro*** \\ Paulo César Dias ${ }^{* * * *}$
}

\section{Resumo}

O papel dos pais no processo de inclusão de crianças com necessidades educativas especiais é fundamental, seja no apoio familiar, seja desmontando mitos e criando um contexto favorável à experiência e à proximidade entre todas as crianças. $\mathrm{O}$ objetivo deste trabalho é, assim, conhecer as percepçôes dos pais relativamente à inclusão, assim como os fatores que as influenciam. Para isso, foi aplicado um inquérito a 300 pais, com filhos com e sem necessidades educativas especiais. Os resultados permitiram perceber atitudes genericamente positivas, sem diferenças relativamente ao gênero e ao fato de serem pais de crianças com necessidades educativas especiais. Contudo, as variáveis idade, escolaridade e proximidade/contato pareceram influenciar a percepção em relação à inclusão de crianças NEE. Assim, os pais com atitudes mais favoráveis à inclusão tendem a ser os mais novos, com maior escolaridade e que tiveram proximidade/contato com criança $\mathrm{NEE}$. Os resultados são discutidos em função da literatura.

Palavras-chave: Inclusão; Pais; Percepção; Educação Especial.

\footnotetext{
* Professora do Ensino Básico, 20 ciclo, variante de Educação Fisica, mestre em Educação Especial pelo Instituto Superior de Ciências Educativas de Felgueiras. Fafe, Portugal.

** Professora do Ensino Básico, $2^{\circ}$ ciclo, variante de Educação Fisica , mestre em Educação Especial pelo Instituto Superior de Ciências Educativas de Felgueiras. Felgueiras, Portugal.

*** Professora do Ensino Básico, $2^{\circ}$ ciclo, variante de Português Francês, mestre em Educação Especial pelo Instituto Superior de Ciências Educativas de Felgueiras. Felgueiras, Portugal.

**** Professor doutor da Universidade Católica Portuguesa. Lisboa, Portugal.
} 


\section{Parents' perception regarding inclusion of children with Special Educational Needs in mainstream education}

\section{Abstract}

The parents' role in the inclusion of children with special needs process is critical, both in family support, but also discussing myths and creating an environment conducive to the experience and proximity among all children. The objective of this work is thus to know more about the parents perceptions regarding inclusion as well as the factors influencing them. For this, a survey of 300 parents with and without children with special educational needs was applied. The results allowed perceive generally positive attitudes, no differences regarding gender and the fact that they are parents of children with special educational needs. However the variables age, education and proximity/contact appear to influence the perception regarding the inclusion of SEN children. Thus, parents with more inclusive attitudes tend to be younger, with higher qualifications and proximity/contact with SEN children. Results are discussed in terms of literature.

Keywords: Inclusion; Parents; Perceptions; Special Education.

\section{Introdução}

Nos últimos anos temos assistido a uma mudança progressiva no sentido da inclusão de crianças e jovens com Necessidades Educativas Especiais (NEE) nas escolas regulares. Duas décadas depois da Declaração de Salamanca (UNESCO, 1994), um importante marco na defesa de uma educação para todos, percebemos maior adaptação das escolas, melhorias na formação inicial de professores, aparecimento de novos percursos de formação contínua, mudanças na legislação, nos recursos e nos meios para as escolas promoverem a inclusão. Também ao nível dos currículos se inscrevem os princípios e valores, no qual consta o respeito e valorização de todos os indivíduos para que desenvolvam "as competências, concebidas como saberes em uso, necessárias à qualidade da vida pessoal e social de todos os cidadãos" (PORTUGAL, 2001, p.15). Finalmente, em termos de investigação, percebe-se a valorização progressiva destes temas, dando origem a diversos ensaios e artigos de reflexão sobre as políticas educativas, trabalhos centrados nos recursos e nas políticas das escolas, na formação, nas atitudes e comportamentos dos agentes educativos.

Num contexto de tanta discussão sobre a aprendizagem dos alunos e a qualidade de respostas, questionam-se, naturalmente, como acolher e envolver estas crianças e adolescentes em todas as atividades de aprendizagem escolar (GLAT, 1995), num processo que exige uma adaptaçáo de todo o contexto, que envolve a sociedade e as comunidades educativas, das instituiçóes, aos diretores, professores, aos pais. Embora muito se tenha falado sobre inclusáo entre os agentes educativos, menor parece ser a investigação produzida sobre as percepções dos pais sobre a inclusão (PALMER; BORTHWICK-DUFFY; WIDAMAN, 1998). No entanto, o seu papel é essencial 
enquanto co-construtores do sistema educativo, a nível político e social, seja através do seu envolvimento e na complementaridade que podem ter na intervenção educativa, na forma como transmitem mensagens para a escola e para os seus filhos, podendo influenciar as percepções que estes têm sobre os seus pares (BARBOSA; ROSINI; PEREIRA, 2007; BATISTA; ENUMO, 2004). As mensagens, explícitas e/ou implícitas, as atitudes e os comportamentos dos pais de crianças com e sem necessidades especiais, são essenciais para o sucesso da educação inclusiva, dado o seu impacto nas atitudes e nos comportamentos dos seus filhos, mas, também, a sua influência sobre as respostas das escolas e dos professores, assim como na influência das políticas educativas. Nos últimos anos, contudo, a investigaçáo tem-se diversificado, permitindo ter, hoje, uma visão mais clara sobre as percepçôes dos pais e os desafios dessa informação para a implementação de uma escola inclusiva. Com a construção de novos instrumentos (e.g.: BARBOSA; ROSINI; PEREIRA, 2007; PALMER; BORTHWICK-DUFFY; WIDAMAN,1998; STOIBER; GETTINGER; GOETZ, 1998), um impulso significativo tem sido registado na investigação sobre as percepçóes dos pais sobre a inclusão, como denotam alguns estudos de revisão (FERRONI; CIA, 2014).

Considerando a falta de estudos centrados sobre esta população em Portugal, pretendemos, com este trabalho, explorar as percepçóes dos pais face à inclusão de crianças com necessidades educativas especiais, nas salas de aula do ensino regular, comparando, em particular, as percepçôes dos pais com e sem filhos com necessidades especiais, assim como com maior ou menor proximidade com pessoas com necessidades especiais.

\section{Percepção dos pais relativamente à inclusão educativa}

Para que uma criança, com ou sem NEE, cresça saudavelmente em todos os domínios do seu funcionamento, a família tem um papel essencial, seja pelas características do contexto como nas relaçóes estabelecidas entre os seus membros, num processo contínuo e intergeracional (CIGOLI; SCABINI, 2006; PEREIRA-SILVA; DESSEN, 2001; PEREIRA-SILVA; DESSEN, 2007). Na realidade, a família cria e recria, na sua dinâmica, a realidade social em que está inserida e disponibiliza as condiçóes para que as crianças desenvolvam as competências necessárias para uma vida em sociedade, disponibilizando um espaço e as condiçôes para proporcionar uma boa qualidade de vida (e.g.: BERTELLI et al., 2011; CONGER; DONNELLAN, 2007; FAN; CHEN, 2001; JEYNES, 2005).

Embora a literatura registre resultados divergentes quanto ao impacto da criança com NEE na família, tal não deixa de implicar um desafio aos recursos, às crenças e expectativas dos pais, dependendo de múltiplos fatores o maior ou menor ajustamento (FIAMENGHI JR; MESSA, 2007; PEREIRA-SILVA; DESSEN, 2006; PINTO; MACEDO; DIAS, 2012). Como percebemos na literatura, têm sido relatadas as dificuldades acrescidas destas famílias, os receios, as inseguranças ou as resistências em relação à inclusão dos filhos na rede de ensino regular, ou a significativa preocupação pelo desenvolvimento das competências motoras ou cognitivas que permitam aos seus filhos alguma autonomia (BARBOSA; ROSINI; PEREIRA, 2007; MELO; MARTINS, 2003; PINTO; MORGADO, 2012). Todos estes desa- 
fios têm sido, em parte, o motivo para o envolvimento das famílias em movimentos civis na qualidade das respostas e do acompanhamento destas crianças nas escolas, na mudança das políticas educativas e mesma na visão sobre estas crianças (STOIBER, GETTINGER, GOETZ, 1998). No entanto, os estudos, mesmo comparando as realidades como a portuguesa com a brasileira (SOUZA, 2007), reforçam ainda uma tendência para ser o aluno a adaptar-se à escola, em vez de uma adaptação do contexto às características da criança.

Muitas vezes, as dificuldades no processo inclusivo decorrem da dificuldade da escola em criar oportunidades para a troca de informaçóes e estratégias, estando mais focalizadas na limitação de problemas ocorridos (FERRAZ; ARAÚJO; CARREIRO, 2010). Também a distância entre o que os pais julgam ser o ideal para os seus filhos e aquilo que acontece na realidade, gerando um sentimento de tristeza, desilusão e frustraçáo, que faz com que os pais possam sentir o processo como de risco para o desenvolvimento dos filhos (SMEHA; OLIVEIRA, 2014). A isso tem sido muito associado o deficit de formaçáo ou preparação dos profissionais, uma das questóes mais investigadas na literatura e corroborada em diversos estudos (e.g.: FERRAZ; ARAÚJO; CARREIRO, 2010; LEONARDO, 2008; MELLO; MARTINS, 2007; VITALIANO, 2007).

A verdade é que, apesar do avanço no conhecimento e na formação dos professores e proximidade de crenças entre os professores e os pais, especialmente no que diz respeito à necessidade do apoio e do envolvimento da família (CHRISTOVAM; CIA, 2013; PEREIRA-SILVA; DESSEN, 2007), os resultados mostram uma tendência para uma percepção mais positiva sobre a inclusão ao nível do seu impacto social, seja termos de aceitação das diferenças pelos pares e pela sociedade, mantendo-se as dúvidas em relação à qualidade das respostas educativas, propriamente ditas, que as crianças recebem (PALMER; BORTHWICK-DUFFY; WIDAMAN, 1998; PINTO; MORGADO, 2012; RAFFERTY, BOETTCHER \& GRIFFIN 2001; SMEHA; OLIVEIRA, 2014). Estas dúvidas aliam-se, também, a expectativas muito fortes dos pais em áreas como a leitura, a escrita e o domínio da linguagem oral, competências que são facilmente associadas à capacidade de adaptação dos filhos ao ambiente em que se inserem e em relação ao futuro (FERRAZ; ARAÚJO; CARREIRO, 2010; PEREIRA-SILVA; DESSEN, 2007). Numa análise diferencial, essas expectativas e atitudes tendem a ser mais favoráveis entre pais que tiveram já algum contato com a realidade inclusiva (PINTO; MORGADO, 2012), ou entre os pais de alunos com NEE (BARBOSA; ROSINI; PEREIRA, 2007; STOIBER; GETTINGER; GOETZ, 1998), sendo independentes de variáveis como o gênero ou o nível de escolaridade (BARBOSA; ROSINI; PEREIRA, 2007; TAFA; MANOLITSIS, 2003).

Considerando o papel essencial dos pais na promoção da escola inclusiva, com o presente estudo pretendemos perceber quais os fatores que influenciam a percepção dos pais de alunos do primeiro ciclo do Ensino Básico, em relação à inclusão de alunos com NEE na sala de aula no ensino regular. Com esses dados, esperamos contribuir para o conhecimento das percepçôes dos pais sobre a inclusão e, a partir daí, perceber novas linhas de ação e intervenção para uma efetiva escola para todos. 


\section{Método}

\section{Amostra}

A amostra, de conveniência, foi constituída por 300 indivíduos, $71.3 \%$ de mulheres $(\mathrm{n}=214)$, com uma média de idades de 37.2 anos ( $\mathrm{DP}=6.0$ anos). Quando inquiridos acerca do nível de escolaridade, como se percebe pela tabela abaixo, a maioria tem o $3^{\circ}$ ciclo $(28.3 \%)$, ou $2^{\circ}$ ciclo $(21.7 \%)$. Das respostas, percebe-se que $35 \%$ são pais de alunos no $4^{\circ}$ ano de escolaridade, $22.6 \%$ de $3^{\circ}$ ano, com os $42.4 \%$ equitativamente distribuídos pelo $1^{\circ}$ e $2^{\circ}$ anos. Dos inquiridos, $70.3 \%$ não têm filhos com NEE, $34.7 \%$ referiram que os seus filhos têm colegas com NEE na sua turma e $59.5 \%$ afirmaram que já tiveram contato ou têm alguma pessoa próxima com Necessidades Educativas Especiais.

Tabela 1: Descrição da amostra.

\begin{tabular}{|c|c|c|c|}
\hline & & Frequência & Porcentagem \\
\hline \multirow{2}{*}{ Gênero } & Masculino & 86 & 28.7 \\
\hline & Feminino & 214 & 71.3 \\
\hline \multirow{7}{*}{ Nível de Escolaridade } & $1^{\circ}$ Ciclo & 36 & 12.4 \\
\hline & $2^{\circ}$ Ciclo & 63 & 21.7 \\
\hline & $3^{\circ}$ Ciclo & 82 & 28.3 \\
\hline & Ensino Secundário & 57 & 19.7 \\
\hline & Licenciatura & 35 & 12.1 \\
\hline & Outros & 2 & 0.7 \\
\hline & Sem formação & 15 & 5.1 \\
\hline \multirow{4}{*}{ Ano de Escolaridade do(s) educando(s) } & $1^{\circ}$ ano & 63 & 21.2 \\
\hline & $2^{\circ}$ ano & 63 & 21.2 \\
\hline & $3^{\circ}$ ano & 67 & 22.6 \\
\hline & $4^{\circ}$ ano & 104 & 35 \\
\hline \multirow{2}{*}{ Tem algum filho com NEE? } & $\operatorname{Sim}$ & 89 & 29.7 \\
\hline & Não & 211 & 70.3 \\
\hline \multirow{2}{*}{$\begin{array}{l}\text { Tem alguma criança na sala do seu } \\
\text { filho com NEE? }\end{array}$} & Sim & 104 & 37.5 \\
\hline & Não & 173 & 62.5 \\
\hline \multirow{2}{*}{$\begin{array}{l}\text { Alguma vez teve contato ou tem } \\
\text { alguma pessoa próxima com NEE? }\end{array}$} & $\operatorname{Sim}$ & 176 & 59.5 \\
\hline & Náo & 115 & 40.5 \\
\hline
\end{tabular}

\section{Instrumento}

Este estudo foi realizado com o recurso de um questionário com três partes. Com a parte I, pretendemos recolher os dados sociodemográficos, como: sexo, idade, nível de escolaridade, ano de escolaridade do educando, se tem algum filho com NEE, 
alguma criança na sala do seu filho com NEE e, por fim, se alguma vez teve contato ou se tem alguma pessoa próxima com NEE.

$\mathrm{Na}$ parte II, foi utilizado um questionário traduzido e adaptado do $M y$ Thinking About Inclusion, desenvolvido por Stoiber, Gettinger e Goetz (1998). Com ele, procuramos analisar o grau de concordância ou discordância relativamente aos 28 itens, que permitem avaliar as concepçôes gerais sobre a inclusão, os resultados esperados e as práticas dos professores. Para isso, os inquiridos podem responder de acordo com uma escala de tipo likert com 5 opçóes, desde 1 - discordo totalmente a 5 - concordo totalmente.

$\mathrm{Na}$ terceira parte, eram apresentadas diferentes Necessidades Educativas Especiais, para recolher a percepção dos pais sobre: o grau de inclusão dos alunos com NEE em salas de aula regular, utilizando uma escala com 4 opçóes de resposta:1 muito apropriado, 2 - apropriado, 3 - inapropriado e 4 - muito inapropriado; o sentido de preparação da escola para promover a inclusão de alunos com NEE nas salas de aula regular, utilizando uma escala de 4 itens: 1 - muito preparado, 2 - preparado, 3 - pouco preparado e 4 - náo preparado.

\section{Procedimentos}

Para a realização do trabalho, foram recolhidas autorizaçóes dos autores dos instrumentos e de diversas escolas do norte de Portugal, escolhidas por uma questão de proximidade geográfica, para a distribuição dos questionários aos pais dos alunos do $1^{\circ}$ Ciclo do Ensino Básico (CEB). Após o contato e autorização da Direçáo dos Agrupamentos de Escolas, foi dado a conhecer aos professores, no sentido de esclarecer os objetivos e procurando definir quais as datas e os horários para administração aos pais. Os questionários foram distribuídos nas reunióes com os professores titulares de turma com a devida explicação dos objetivos do estudo, assim como o caráter voluntário e anônimo da sua participação. Depois de recolhidos, os dados foram codificados e introduzidos no programa de tratamento estatístico Statistical Package for Social Sciences (SPSS), versão 15, no sentido de se proceder à análise e tratamento dos dados.

\section{Resultados}

A partir dos dados recolhidos, foram efetuadas estatísticas descritivas e inferenciais, que nos permitiram compreender melhor como os pais percebem a inclusão de crianças com NEE e explorar fatores que influenciam a sua percepção sobre a inclusão em contexto escolar. 


\section{Percepções dos pais sobre a inclusão educativa e grau de preparação das escolas}

Numa leitura descritiva das respostas da amostra, apresentadas na tabela 2, percebemos, genericamente, respostas positivas em relaçáo aos benefícios da inclusão educativa. Destacam-se as percepçóes positivas relativamente à importância dos professores de Educação Especial na gestão de turmas inclusivas que, embora se perceba que possam exigir maior atençáo por parte dos professores, as oportunidades e desafios da aprendizagem em sala de aula são a melhor forma de promover a evoluçáo das crianças com NEE. Analisando as pontuações médias mais baixas, percebemos ainda que os pais percebem os benefícios da inclusáo para os alunos como um desenvolvimento normal e que a exclusão dos alunos em salas de educação especial pode ter um efeito negativo no desenvolvimento social e emocional de crianças com Necessidades Especiais.

Tabela 2: Porcentagem e média da amostra em relação à inclusão (Continua).

\begin{tabular}{|c|c|c|c|c|c|c|}
\hline Item & DT & D & I & $\mathrm{C}$ & CT & Média \\
\hline $\begin{array}{l}\text { 1. Os alunos com NEE's têm o direito de ser } \\
\text { educados nas mesmas classes que os demais } \\
\text { alunos. }\end{array}$ & 4.0 & 6.4 & 15.2 & 39.7 & 34.7 & 3.95 \\
\hline $\begin{array}{l}\text { 2. A inclusão não é uma prática benéfica } \\
\text { para educar alunos com um nível de } \\
\text { desenvolvimento normal. }\end{array}$ & 18.8 & 20.9 & 30.5 & 20.9 & 8.9 & 2.80 \\
\hline $\begin{array}{l}\text { 3. É difícil manter a ordem numa classe com } \\
\text { alunos com NEE e alunos sem NEE. }\end{array}$ & 13.5 & 24.2 & 21.9 & 27.3 & 13.1 & 3.02 \\
\hline $\begin{array}{l}\text { 4. Às crianças com NEE devem ser dadas as } \\
\text { oportunidades adequadas à sua integração } \\
\text { numa sala de aula regular. }\end{array}$ & 2.0 & 4.4 & 10.2 & 43.4 & 40.4 & 4.15 \\
\hline $\begin{array}{l}\text { 5. A inclusão pode ser benéfica para os pais de } \\
\text { alunos com NEE. }\end{array}$ & 4.4 & 7.8 & 25.1 & 38.0 & 24.7 & 3.71 \\
\hline $\begin{array}{l}\text { 6. Os pais de alunos com NEE preferem } \\
\text { que os seus filhos frequentem salas de aula } \\
\text { regulares. }\end{array}$ & 3.1 & 4.8 & 32.6 & 41.9 & 17.5 & 3.36 \\
\hline $\begin{array}{l}\text { 7. A maioria dos professores de educação } \\
\text { especial não possui conhecimentos } \\
\text { apropriados para ensinar alunos com } \\
\text { desenvolvimento normal. }\end{array}$ & 10.7 & 30.8 & 32.4 & 20.1 & 6.0 & 2.80 \\
\hline $\begin{array}{l}\text { 8. As necessidades específicas de alunos com } \\
\text { limitaçóes náo podem ser atendidas de forma } \\
\text { adequada por professores do ensino regular. }\end{array}$ & 7.1 & 18.2 & 25.6 & 32.7 & 16.5 & 3.33 \\
\hline $\begin{array}{l}\text { 9. É necessário aprendermos mais sobre os } \\
\text { efeitos de haver classes inclusivas antes de } \\
\text { adotar esse conceito a larga escala. }\end{array}$ & 0.7 & 5.1 & 22.6 & 47.8 & 23.9 & 3.89 \\
\hline
\end{tabular}


Continuaçăo Tabela 2.

\begin{tabular}{|c|c|c|c|c|c|c|}
\hline $\begin{array}{l}\text { 10. A melhor forma de começar a educar } \\
\text { alunos com NEE em escolas inclusivas é } \\
\text { simplesmente fazendo-o. }\end{array}$ & 5.4 & 14.2 & 21.7 & 44.7 & 13.9 & 3.48 \\
\hline $\begin{array}{l}\text { 11. A maioria dos alunos com NEE comporta- } \\
\text { se bem em salas de aula regular. }\end{array}$ & 5.8 & 19.3 & 43.7 & 6.0 & 7.5 & 3.08 \\
\hline $\begin{array}{l}\text { 12. É possível ensinar alunos com NEE e sem } \\
\text { NEE na mesma sala de aula. }\end{array}$ & 3.8 & 16.4 & 28.1 & 40.4 & 11.3 & 3.39 \\
\hline $\begin{array}{l}\text { 13. A inclusão é socialmente vantajosa para os } \\
\text { alunos com NEE. }\end{array}$ & 3.7 & 7.5 & 26.2 & 41.8 & 20.7 & 3.68 \\
\hline $\begin{array}{l}\text { 14. Os alunos com NEE provavelmente } \\
\text { desenvolvem mais rapidamente as suas } \\
\text { capacidades acadêmicas numa sala de aula } \\
\text { separada, com os serviços de educaçáo especial, } \\
\text { do que numa sala de aula regular. }\end{array}$ & 6.1 & 19.1 & 24.6 & 34.5 & 15.7 & 3.35 \\
\hline $\begin{array}{l}\text { 15. Os alunos com NEE podem facilmente ser } \\
\text { colocados à parte pelos outros alunos nas salas } \\
\text { de aula. }\end{array}$ & 10.3 & 24.8 & 23.4 & 30.7 & 10.7 & 3.07 \\
\hline $\begin{array}{l}\text { 16. A presença de crianças com NEE } \\
\text { promove a aceitação das suas diferenças } \\
\text { individuais por parte dos seus colegas com um } \\
\text { desenvolvimento normal. }\end{array}$ & 1.7 & 5.4 & 22.4 & 41.0 & 29.5 & 3.91 \\
\hline $\begin{array}{l}\text { 17. A inclusão promove uma maior } \\
\text { independência social e autonomia nos alunos } \\
\text { com NEE. }\end{array}$ & 3.8 & 4.1 & 28.3 & 41.6 & 22.2 & 3.74 \\
\hline $\begin{array}{l}\text { 18. A inclusão fomenta uma maior autoestima } \\
\text { nos alunos com NEE. }\end{array}$ & 4.8 & 7.1 & 25.9 & 20.8 & 21.4 & 3.67 \\
\hline $\begin{array}{l}\text { 19. As crianças com NEE podem apresentar } \\
\text { comportamentos mais desafiadores e } \\
\text { perturbadores nas salas de aula regulares que } \\
\text { nas salas de Educaçáo Especial. }\end{array}$ & 3.7 & 15.3 & 35.9 & 34.2 & 10.8 & 3.33 \\
\hline $\begin{array}{l}\text { 20. Os alunos com NEE nas salas de } \\
\text { aula regulares desenvolvem um melhor } \\
\text { autoconceito e conhecimento de si mesmos } \\
\text { do que numa sala de Educação Especial. }\end{array}$ & 5.0 & 11.7 & 32.1 & 36.5 & 14.7 & 3.44 \\
\hline $\begin{array}{l}\text { 21. Os desafios e as situaçóes próprias de uma } \\
\text { sala de aula regular promovem uma maior } \\
\text { evolução acadêmica nas crianças com NEE. }\end{array}$ & 2.7 & 13.3 & 28.9 & 42.2 & 12.9 & 4.49 \\
\hline 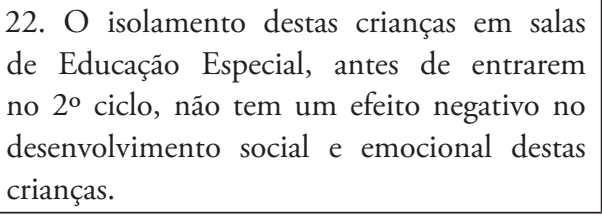 & 13.3 & 27.2 & 36.1 & 16.0 & 7.5 & 2.77 \\
\hline
\end{tabular}


Continuação Tabela 2.

\begin{tabular}{|c|c|c|c|c|c|c|}
\hline $\begin{array}{l}\text { 23. Os alunos com um desenvolvimento } \\
\text { normal, inseridos em salas de aula inclusivas, } \\
\text { têm mais hipóteses de apresentar um } \\
\text { comportamento desafiador e perturbador, } \\
\text { aprendido com os seus colegas com NEE. }\end{array}$ & 7.5 & 29.6 & 32.7 & 21.1 & 9.2 & 2.95 \\
\hline $\begin{array}{l}\text { 24. Os alunos com NEE monopolizam o } \\
\text { tempo dos professores durante as aulas. }\end{array}$ & 4.4 & 17.0 & 34.7 & 32.7 & 11.2 & 3.29 \\
\hline $\begin{array}{l}\text { 25. O comportamento dos alunos com NEE } \\
\text { requer uma atenção muito maior por parte } \\
\text { dos professores do que necessitam os alunos } \\
\text { com um desenvolvimento normal. }\end{array}$ & 1.7 & 7.0 & 9.4 & 50.3 & 31.5 & 4.03 \\
\hline $\begin{array}{l}\text { 26. Os pais de alunos com NEE necessitam } \\
\text { de mais apoios complementares por parte } \\
\text { dos professores do que necessitam os pais de } \\
\text { alunos com um desenvolvimento normal. }\end{array}$ & 2.0 & 8.8 & 17.6 & 46.4 & 25.1 & 3.84 \\
\hline $\begin{array}{l}\text { 27. Os pais de alunos com NEE náo } \\
\text { representam um maior desafio para os } \\
\text { professores do ensino regular do que } \\
\text { representam os pais de crianças com um } \\
\text { desenvolvimento normal. }\end{array}$ & 7.1 & 23.6 & 32.1 & 29.7 & 7.4 & 3.07 \\
\hline $\begin{array}{l}\text { 28. Uma boa forma de gerir turmas inclusivas } \\
\text { é ter um professor de Educação Especial } \\
\text { responsável pelo ensino de crianças com NEE. }\end{array}$ & 0.3 & 5.4 & 12.9 & 41.7 & 39.7 & 4.15 \\
\hline
\end{tabular}

Nota: DT - Discordo Totalmente; D - Discordo; I - Indeciso; C - Concordo; CT - Concordo Totalmente.

Quando analisados os itens referentes à percepção dos pais sobre a inclusão de alunos e o sentido de preparação das escolas para a inclusão de alunos com NEE em salas de aula regular, verificamos diferenças nas respostas em função das NEE dos alunos. Como se percebe da tabela a seguir (tabela 3), os pais parecem ter uma percepção de inclusão apropriada dos alunos com problemas de Fala e Linguagem e com Perturbaçóes Emocionais, apontando como menos apropriada a inclusão de alunos com Perturbação Neurológica/Lesões Cerebrais, Deficiência Mental Moderada/Severa e Autismo/Perturbação Global do Desenvolvimento. Quando tentamos perceber em que medida as escolas estão preparadas para lidar com alunos com diferentes Necessidades Especiais, os inquiridos afirmaram que a escola está mais preparada para promover a inclusão no ensino regular de crianças com deficiência física e motora ou perturbação emocional e menos preparadas para apoiar alunos com Perturbação Neurológica/Lesōes Cerebrais ou Autismo/Perturbação Global do Desenvolvimento. 
Tabela 3: Grau de inclusão e de preparação das escolas em função da perturbação (\%).

\begin{tabular}{|c|c|c|c|c|c|c|c|c|c|c|}
\hline \multicolumn{6}{|c|}{ Grau de inclusão de crianças NEE } & \multicolumn{5}{|c|}{ Grau de preparação } \\
\hline & MA & A & I & MI & Média & MP & $\mathrm{P}$ & $\mathrm{PP}$ & NP & Média \\
\hline $\begin{array}{l}\text { Problemas de Fala } \\
\text { e Linguagem }\end{array}$ & 22.3 & 51.7 & 19.9 & 6.1 & 2.10 & 13.1 & 7.4 & 9.8 & 9.7 & 2.36 \\
\hline $\begin{array}{l}\text { Deficiência } \\
\text { Mental Ligeira }\end{array}$ & 15.4 & 50.9 & 25.3 & 8.4 & 2.27 & 13.5 & 44.1 & 31.6 & 10.8 & 2.40 \\
\hline $\begin{array}{l}\text { Deficiência } \\
\text { Mental Moderada/ } \\
\text { Severa }\end{array}$ & 11.5 & 23.6 & 41.0 & 23.9 & 2.78 & 17.1 & 20.2 & 35.5 & 27.2 & 2.73 \\
\hline $\begin{array}{l}\text { Perturbação de } \\
\text { Hiperatividade } \\
\text { e Déficit de } \\
\text { Atençáo }\end{array}$ & 16.0 & 47.6 & 28.5 & 7.9 & 2.28 & 15.1 & 39.6 & 33.3 & 12.0 & 2.42 \\
\hline Deficiência Visual & 20.3 & 42.6 & 26.1 & 11.0 & 2.28 & 19.1 & 26.0 & 34.4 & 20.5 & 2.56 \\
\hline $\begin{array}{l}\text { Deficiência } \\
\text { Auditiva }\end{array}$ & 14.5 & 48.1 & 26.6 & 10.8 & 2.34 & 17.1 & 28.7 & 36.0 & 18.2 & 2.55 \\
\hline $\begin{array}{l}\text { Deficiência Física } \\
\text { e Motora }\end{array}$ & 21.6 & 44.6 & 25.1 & 8.7 & 2.21 & 21.1 & 37.9 & 26.7 & 14.3 & 2.34 \\
\hline $\begin{array}{l}\text { Perturbação } \\
\text { Emocional }\end{array}$ & 16.0 & 54.7 & 25.1 & 4.2 & 2.17 & 14.1 & 45.4 & 32.4 & 8.1 & 2.35 \\
\hline $\begin{array}{l}\text { Problemas de } \\
\text { Comportamento }\end{array}$ & 17.8 & 49.0 & 27.6 & 5.6 & 2.21 & 13.4 & 43.7 & 32.4 & 10.5 & 2.40 \\
\hline $\begin{array}{l}\text { Perturbação } \\
\text { Neurológica/ } \\
\text { Lesóes } \\
\text { Cerebrais }\end{array}$ & 10.5 & 23.9 & 40.0 & 25.6 & 2.81 & 15.7 & 19.9 & 31.8 & 32.6 & 2.81 \\
\hline $\begin{array}{l}\text { Autismo/ } \\
\text { Perturbação } \\
\text { Global do } \\
\text { Desenvolvimento }\end{array}$ & 14.0 & 26.9 & 38.1 & 21.0 & 2.66 & 15.7 & 20.3 & 38.5 & 25.5 & 2.74 \\
\hline
\end{tabular}

Nota: MA - Muito Apropriado; A - Apropriado; I - Inapropriado; MI - Muito Inapropriado; MP - Muito Preparado; P - Preparado; PP - Pouco Preparado; NP - Não Preparado.

\section{Percepções dos pais em função de variáveis pessoais}

Integrando os itens de cada uma das dimensões da escala, foram estudadas, com o recurso de estatísticas inferenciais, as relaçôes ou dependências da percepção dos pais em relação às subescalas do MTAI, função de variáveis pessoais como o gênero, a idade e o nível de escolaridade. Se em função do gênero, não se verificaram diferenças $(\mathrm{p}>.05)$, na relação com a idade foi encontrada uma correlação margi- 
nalmente significativa entre a variável Idade e o índice Práticas $(\mathrm{p}=-, 117, \mathrm{p}=, 051)$. Já em relação à escolaridade, foi encontrada uma relação positiva e estatisticamente significativa com os Resultados Esperados $(\mathrm{r}=.324, \mathrm{p}<.05)$, e marginalmente significativa com as Concepçóes Gerais $(r=.120, \mathrm{p}=.058)$.

\section{Percepções dos pais em função da proximidade com alunos com NEE}

Na tabela abaixo (tabela 4), apresentam-se os resultados das percepçóes sobre a inclusão em função da proximidade com crianças e jovens com NEE. Para isso, foram tidas em consideração as questôes "Tem algum filho com NEE?", "Tem alguma criança na sala do seu filho com NEE?" e "Alguma vez teve contato ou tem alguma pessoa próxima com NEE?".

Dos resultados percebemos que não existem diferenças nas pontuaçóes médias entre os pais de alunos com NEE e os que não têm filhos com NEE. Já em função da proximidade com crianças com NEE na sala de aula e no seu contexto pessoal, perceberam-se algumas diferenças. Entre os pais com criança com NEE na sala do seu filho, foram verificadas diferenças nas "Concepçóes Gerais" $(\mathrm{t}(239)=2.372, \mathrm{p}$ $<.05)$ e "Resultados Esperados" ( $\mathrm{t}(242)=2.210, \mathrm{p}<.05)$. Também entre pais que tem contato ou tem alguma pessoa próxima com NEE, verificaram-se diferenças nas mesmas dimensóes "Concepçôes Gerais" ( $\mathrm{t}(249)=2.077, \mathrm{p}<.05)$, "Resultados Esperados" $(\mathrm{t}(253)=3.800, \mathrm{p}<.05)$.

Tabela 4 - Percepção dos pais em função da proximidade com pessoas com NEE.

\begin{tabular}{|c|c|c|c|c|c|c|c|c|}
\hline & \multicolumn{2}{|c|}{ Sim } & \multicolumn{2}{|c|}{ Não } & \multicolumn{3}{|c|}{ Test $\mathrm{t}$} \\
\hline & & M & $\mathrm{DP}$ & M & $\mathrm{DP}$ & $\mathrm{t}$ & $\mathrm{gl}$ & $\mathrm{p}$ \\
\hline \multirow{3}{*}{$\begin{array}{l}\text { Pais de filhos } \\
\text { com e sem } \\
\text { NEE }\end{array}$} & $\begin{array}{l}\text { Concepçóes } \\
\text { gerais }\end{array}$ & 39.25 & 5.90 & 39.94 & 6.16 & -.819 & 258 & .414 \\
\hline & $\begin{array}{l}\text { Resultados } \\
\text { esperados }\end{array}$ & 36.51 & 6.26 & 36.95 & 6.43 & -.508 & 262 & .612 \\
\hline & Práticas & 11.63 & 3.02 & 11.73 & 2.60 & -.268 & 281 & .775 \\
\hline \multirow{3}{*}{$\begin{array}{l}\text { Proximidade } \\
\text { com crianças } \\
\text { com NEE }\end{array}$} & $\begin{array}{l}\text { Concepçóes } \\
\text { gerais }\end{array}$ & 40.84 & 5.98 & 38.93 & 6.17 & 2.372 & 239 & .018 \\
\hline & $\begin{array}{l}\text { Resultados } \\
\text { esperados }\end{array}$ & 37.89 & 6.82 & 36.40 & 6.01 & 2.210 & 242 & .028 \\
\hline & Práticas & 11.64 & 2.98 & 11.67 & 2.66 & -.100 & 261 & .920 \\
\hline \multirow{3}{*}{$\begin{array}{l}\text { Contato } \\
\text { ou pessoa } \\
\text { próxima } \\
\text { com NEE }\end{array}$} & $\begin{array}{l}\text { Concepçôes } \\
\text { gerais }\end{array}$ & 40.49 & 5.90 & 38.86 & 6.36 & 2.077 & 249 & .039 \\
\hline & $\begin{array}{l}\text { Resultados } \\
\text { esperados }\end{array}$ & 38.09 & 6.24 & 35.12 & 6.00 & 3.800 & 253 & .000 \\
\hline & Práticas & 11.47 & 2.63 & 11.98 & 2.82 & -1.542 & 272 & .124 \\
\hline
\end{tabular}

Nota: M - Média; DP - Desvio Padráo; t - teste t de student; gl - graus de liberdade; p - significância. 


\section{Discussão}

O presente estudo pretendia conhecer as percepçôes dos pais sobre a inclusão. Apesar de este ser um fenômeno já legislado em Portugal ainda antes da Declaração de Salamanca (UNESCO, 1994), desde a Lei de Bases do Sistema Educativo (1986), e, mais especificamente, desde o DL 319 de 1991, discute-se a sua tradução plena na realidade das escolas portuguesas, seja pelas dificuldades nas respostas e na eficácia do acompanhamento das crianças e das famílias. À falta de investigação junto desta população, este estudo contribuiu para uma primeira leitura, descritiva e inferencial, sobre as suas percepçôes em relação à inclusão educativa.

Os resultados apresentados permitem obter percepçóes positivas em relação à inclusão, em linha com a literatura (e.g.: BARBOSA; ROSINI; PEREIRA, 2007; BENNET; DELUCA; BRUNS, 1997; PINTO; MORGADO, 2012; STOIBER; GETTINGER; GOETZ, 1998; TAFA; MANOLITSIS, 2003), registrando-se que a maioria dos itens foi respondida numa pontuação superior a 3 (numa escala de 1 a 5). No mesmo sentido, os pais apresentam percepções positivas em relação ao grau de inclusão de crianças com NEE na escola e na preparação das escolas para a sua inclusão, sendo as percepçóes menos positivas em perturbaçóes que, à partida, tem consequências mais invasivas e transversais, como seja a Deficiência Mental Moderada/ Severa, Perturbação Neurológica/Lesões Cerebrais ou o autismo. Perante os desafios que estas famílias enfrentam (FIAMENGHI JR; MESSA, 2007; PEREIRA-SILVA; DESSEN, 2006; PINTO; MACEDO; DIAS, 2012), percebe-se a expectativa e a confiança que dedicam aos professores da Educação Especial, no sentido de envolver todos os alunos, com e sem NEE, apesar dos desafios que podem gerar para a gestão do tempo, recursos e atividades.

Também aqui as pontuaçôes encontradas não foram diferentes em função do gênero (BARBOSA; ROSINI; PEREIRA, 2007; TAFA; MANOLITSIS, 2003), embora se tenha percebido uma relação com a escolaridade com os resultados esperados da inclusão (PALMER; BORTHWICK-DUFFY; WIDAMAN, 1998; PINTO; MORGADO, 2012). Isto é, pais mais escolarizados parecem apresentar mais sensibilidade a estes valores, que se refletem numa tendência para perceber mais benefícios, sociais ou desenvolvimentais, para todos alunos, com e sem necessidades especiais.

Além da escolaridade, verificamos que pais que têm na turma dos seus filhos crianças com NEE apresentaram uma atitude mais positiva relativamente ao processo de inclusão (STOIBER; GETTINGER; GOETZ, 1998). Este fundamento é ainda corroborado com a diferença estatisticamente significativa observada na questão "Alguma vez teve contato ou tem alguma pessoa próxima com NEE?”, isto é, pais com maior proximidade com pessoas com necessidades especiais apresentaram uma perspectiva mais positiva relativamente à inclusão educativa. Nesta linha de pensamento, o contato com educaçáo inclusiva apela para uma aprendizagem que veja a criança no seu todo, respeitando o desenvolvimento nas suas diversas vertentes, acadêmica, sócio emocional e pessoal (CORREIA, 1997). É importante realçar que a escola inclusiva descreve-se como um local multicultural e variado, com múltiplas opçóes de respostas e possibilidades, de modo a proporcionar uma educaçấo apropriada e orientada 
para a maximização do potencial de cada. Por conseguinte, trata-se de um paradigma que se constitui como fator de enriquecimento de todos, uma oportunidade de aprendizagem e uma forma de mostrar que cada indivíduo é um ser único e especial (RODRIGUES, 1995). Se o envolvimento e as atitudes dos pais são essenciais para o sucesso educativo dos alunos (ver revisão em HILL; TYSON, 2009), permanece o desafio de melhorar as atitudes dos pais, principalmente os com menos contato com crianças com NEE para a promoção de uma Escola mais justa e democrática.

Dos resultados, perceberam-se também algumas diferenças em relação à literatura, nomeadamente, no que diz respeito às diferenças entre os pais com e sem NEE (BARBOSA; ROSINI; PEREIRA, 2007; STOIBER; GETTINGER; GOETZ, 1998). Estes dados, aliados às pontuaçóes genericamente positivas encontradas, podem sugerir um certo consenso entre todos os pais para a necessidade de criaçáo de um contexto favorável para todas as crianças, independentemente das suas características ou dificuldades. Não obstante, a proximidade com esta população faz com que os pais vejam de forma mais positiva a inclusão de crianças com NEE em turmas regulares (PINTO; MORGADO, 2012). As suas vivências, experiências e necessidades criam desafios e maior sensibilidade para as respostas que as escolas devem dar para promover o desenvolvimento de todos os indivíduos, assim como a promoção dos valores de justiça, democracia e equidade. Podemos, assim, perceber que a proximidade, apesar de tudo, permite uma percepçáo mais positiva sobre o paradigma inclusivo.

\section{Conclusão}

A investigação realizada parece mostrar atitudes positivas dos pais em relação à inclusão de crianças com NEE no ensino regular. A literatura e a experiência sugerem que os pais têm um papel essencial nas mensagens que transmitem aos filhos e para a escola, pelo que estes resultados são encorajadores em relação aos avanços sociais relativamente ao movimento inclusivo.

Apesar destas conclusóes, temos que considerar possíveis limitaçóes do estudo, no que diz respeito às características da amostra, recolhidas por motivos de conveniência, ou da própria metodologia, baseada em questionários, que podem suscitar algumas limitaçóes de desejabilidade social ou de compreensão profunda das questôes por parte dos participantes no estudo. Sendo a inclusão um desígnio social de maior relevância, importa continuar os estudos, com amostras mais diversificadas e, eventualmente, metodologias mistas, que permitam confrontar os dados obtidos nos questionários com outras fontes mais ricas em termos de aprofundamento da informação recolhida. Paralelamente, parece-nos particularmente importante continuar a disseminar informação válida para promover a consciência social e a inclusão nas instituiçóes sociais, desde logo, a partir da escola.

\section{Referências}

BARBOSA, A.; ROSINI, D.; PEREIRA, A. Atitudes parentais em relação à educação inclusiva. Revista Brasileira Educaçáo Especial, Marília, v. 13, n. 3, p. 447-458, set./dez. 2007.

BATISTA, M. W.; ENUMO, S. R. Inclusão escolar e deficiência mental: análise da interacção social entre companheiros. Estudos de Psicologia, Natal, v. 9, n. 1, p. 101-111, 2004. 
BENNETT, T.; DELUCA, D.; BRUNS, D. Putting Inclusion into practice: perspectives of teachers and parents. Exceptional Children, v. 64, n. 1, p. 115-131, 1997.

BERTELLI, M. et al. Relationship between individual quality of life and family quality of life for people with intellectual disability living in Italy. Journal of Intellectual Disability Research, v. 55, n. 12, p. 1136-1150, dez. 2011.

CHRISTOVAM, A. C.; CIA, F. O Envolvimento parental na visão de pais e professores de alunos com necessidades educacionais especiais. Revista Brasileira de Educaçáo Especial, Marília, v. 19, n. 4, p. 563-582, out./ dez. 2013.

CIGOLI, V.; SCABINI, E. Family identity: ties, symbols, and transitions. London: lawrence erlbaum associations, 2006, 236p.

CONGER, R. D.; DONNELLAN, B. An interactionist perspective on the socioeconomic context of human development. Annual Review of Psychology, n. 58, p. 175-199, 2007.

CORREIA, L. Alunos com necessidades educativas especiais nas classes regulares. Porto: Porto Editora, 1997, 175p.

FAN, X.; CHEN, M. Parental involvement and students' academic. Achievement: a meta-analysis. Educational Psychology Review, v. 13, n. 1, p. 1-22, 2001.

FERRAZ, C. R.; ARAÚJO, M. V.; CARREIRO, L. R. Inclusão de crianças com síndrome de down e paralisia cerebral no ensino fundamental i: comparação dos relatos de máes e professores. Revista Brasileira de Educação Especial, Marília, v. 16, n. 3, p. 397-414, set./dez. 2010.

FERRONI, G. M.; CIA, F. Estado da arte em revistas educacionais sobre estudos feitos com famílias de crianças com necessidades educacionais especiais no período de 2002 a 2011. Revista Educaçáo Especial, Santa Maria, v. 27, n. 48, p. 201-218. jan./abr. 2014.

FIAMENGHI, JR.; MESSA, A. Pais, filhos e deficiência: estudos sobre as relaçóes familiares. Psicologia Ciência e Profissáo, Brasilia, v. 27, n. 2, p. 236-245, 2007.

GLAT, R. A integraçáo social dos portadores de deficiência: uma reflexão. Rio de Janeiro: Sete Letras, 1995, $72 \mathrm{p}$.

HILL, N. E.; TYSON, D. F. Parental involvement in middle school: a meta-analytic assessment of the strategies that promote achievement. Developmental Psychology, v. 45, n. 3, p. 740-763, mai. 2009.

JEYNES, W. H. A meta-analysis of the relation of parental involvement to urban elementary school student academic achievement. Urban Education, v. 40, n. 3, p. 237-269, 2005.

LEONARDO, N. S. Inclusão escolar: um estudo acerca da implantação da proposta em escolas públicas. Psicologia Escolar e Educacional, Campinas, v. 12, n. 2, jul./dez. 2008.

MELLO, F. R.; MARTINS, L. A. Acolhendo e atuando com alunos que apresentam paralisia cerebral na classe regular: a organização da escola. Revista Brasileira de Educação Especial, Marília, v. 13, n. 1, p. 111-130, jan./abr. 2007.

MELO, F., \& MARTINS, L. O que pensa a comunidade escolar sobre o aluno com paralisia cerebral. Revista Brasileira Educaçáo Especial, Marília, v. 10, n. 1, p. 75-92, 2003.

PORTUGAL. Ministério da Educaçáo. Currículo nacional do ensino básico: competências essenciais. Lisboa, Ministério da Educação, Departamento de Educação Básica, 2001.

PALMER, D. S.; BORTHWICK-DUFFY, S. A.; WIDAMAN, K. Parent perceptions of inclusive practices for their children with significant cognitive disabilities. Exceptional children, v. 64, p. 271-282, p. 1998.

PEREIRA-SILVA, N.; DESSEN, M. Deficiência mental e família: Implicaçóes para o desenvolvimento da criança. Psicologia: Teoria e Pesquisa, Brasília, v. 17, n. 2, p. 133-141, maio/ago. 2001.

PEREIRA-SILVA, N.; DESSEN, M. Famílias de crianças com síndrome de Down: sentimentos, modos de vida e estresse parental. Interaçáo em Psicologia, Curitiba, v. 10, n. 2, p. 183-194, 2006.

PEREIRA-SILVA, N. L.; DESSEN, M. A. Crianças com e sem síndrome de Down: valores e crenças de pais e professores. Revista Brasileira de Educaçáo Especial, Marília, v. 13, n. 3, p. 429-446, set./dez. 2007.

PINTO, I. M.; MACEDO, C.; DIAS, P.C. Qualidade de vida de famílias com necessidades especiais. Revista Iberoamericana de Educaçáo, n. 63, p. 181-198, set./dez. 2012 
PINTO, N.; MORGADO, J. Atitudes de pais e professores perante a inclusão. In: L. MATA et al. (Org.). Educaçáo, aprendizagem e desenvolvimento: olhares contemporâneos através da investigação e da prática - Actas do 12. ${ }^{\circ}$ Colóquio Internacional de Psicologia e Educação. Lisboa: ISPA - Instituto Universitário, p. 471-491, 2012.

RAFFERTY, Y.; BOETTCHER, C.; GRIFFIN, K. Benefits and risks of reverse inclusion for preschoolers with and without disabilities: parents' perspectives. Journal of Early Intervention, v. 24, p. 266-286, 2001.

RODRIGUES, D. O conceito de necessidades educativas especiais e as novas metodologias em educação. In: CARVAlHO, A. (Org.). Novas metodologias em educaçáo. Porto: Porto Editora, p. 527-548, 1995.

SMEHA, L. N.; OLIVEIRA, V.L. Inclusão escolar: a perspectiva das mães de alunos com Síndrome de Down. Revista Educaçáo Especial, Santa Maria, v. 27, n. 49, p. 403-416, maio/ago. 2014.

SOUZA, J. M. Crianças com necessidades educativas especiais como membro da sociedade e sua inclusão no contexto escolar: estudo de caso comparativo entre Brasil e Portugal. 2007. Dissertação (Mestrado) - Universidade do Minho, Portugal, 2007.

STOIBER, K.; GETTINGER, M.; GOETZ, D. Exploring factors influencing parents' and early childhood practitioners' beliefs about inclusion. Early Childhood Research Quarterly, v. 13, n. 1, p. 107-124, 1998.

TAFA, E.; MANOLITSIS, G. Attitudes of greek parents of typically developing kindergarten children towards inclusive education. European Journal of Special Needs Education, v. 18 n. 2, p. 155-171, 2003.

UNESCO. Declaração de Salamanca e enquadramento da ação na área das necessidades educativas especiais. Conferência Mundial sobre necessidades educativas especiais: acesso e qualidade. Paris, UNESCO, 1994. 48p.

VITALIANO, C. R. Análise da necessidade de preparação pedagógica de professores de cursos de licenciatura para inclusão de alunos com necessidades educacionais especiais. Revista Brasileira de Educaçáo Especial, Marília, v. 13, n. 3, p. 399-414, 2007.

\section{Correspondência}

Elisabete Matos Freitas - Urbanização Sol Poente n. 117. CEP: 4820-122, Fafe - Portugal.

E-mail: elisemia_bi@hotmail.com - luisa.arroja@gmail.com - paularibeirofermil@gmail.com - pcdias@braga. ucp.pt

Recebido em 23 de agosto de 2014

Aprovado em 18 dezembro de 2014 